\title{
Pyramidal Fin Arrays Performance Using Streamwise Anisotropic Materials by Cold Spray Additive Manufacturing
}

\author{
Yannick Cormier, Philippe Dupuis, Bertrand Jodoin, and Antoine Corbeil
}

(Submitted April 16, 2015; in revised form May 28, 2015)

\begin{abstract}
This work evaluates the thermal and hydrodynamic performance of pyramidal fin arrays produced using cold spray as an additive manufacturing process. Near-net-shaped pyramidal fin arrays of pure aluminum, pure nickel, and stainless steel 304 were manufactured. Fin array characterization such as fin porosity level and surface roughness evaluation was performed. The thermal conductivities of the three different coating materials were measured by laser flash analysis. The results obtained show a lower thermal efficiency for stainless steel 304, whereas the performances of the aluminum and nickel fin arrays are similar. This result is explained by looking closely at the fin and substrate roughness induced by the cold gas dynamic additive manufacturing process. The multi-material fin array sample has a better thermal efficiency than stainless steel 304. The work demonstrates the potential of the process to produce streamwise anisotropic fin arrays as well as the benefits of such arrays.
\end{abstract}

Keywords additive manufacturing, cold spray, heat transfer, pin fin array, thermal conductivity

\section{Introduction}

Research focusing on the enhancement of heat exchanger performance has become a priority in areas such as gas turbine development, electronic cooling, and power generation (Ref 1-4). Indeed, heat exchangers have become common components in various engineering disciplines due to the importance and the challenges associated with thermal management. Some of the most widely used heat exchanger designs rely on fin arrays as heat transfer enhancing surfaces to be able to minimize the size and weight of such components for a given heat exchange rate (Ref 1, 4). Enhancing thermal conductance of fin arrays while decreasing the size of heat exchangers is also especially important for the aerospace and automotive industries, for which the weight and volume of components are important factors.

To increase the ratio of heat transfer area per unit volume, fins have tended to become longer and slimmer

This article is an invited paper selected from presentations at the 2015 International Thermal Spray Conference, held May 11-14, 2015, in Long Beach, California, USA, and has been expanded from the original presentation.

Yannick Cormier, Philippe Dupuis, and Bertrand Jodoin, Department of Mechanical Engineering, University of Ottawa, Ottawa, Canada; and Antoine Corbeil, Brayton Energy Canada, Gatineau, Canada. Contact e-mail: yannick.cormier@uottawa.ca. combined with a higher fin density (amount of fins per unit base area). This densification of the fin arrays has some practical limitations based on the manufacturing techniques used to produce these features. Extrusion and machining have typically been used to produce both continuous fin and pin fin arrays, respectively (Ref 5). Casting has also been used as an alternative production method for these arrays (Ref 5). All these manufacturing techniques suffer from the same drawback of increased cost as the complexity and density of the fin array increase (Ref 5). The cost of casting and extrusion increases rapidly due to the precision required for the production of the mold or die (Ref 1, 6), while for machining, the production speed decreases with tool size, which is the limiting factor for feature size and the associated tolerances (Ref 1,7). Metal mold casting is further restrained as the design must accommodate features with taper angles and without concave details so that the part can be removed from the rigid mold after casting (Ref 1,8$)$. When the fin array features are too small for conventional manufacturing techniques, lithographic techniques can be used to produce fin arrays but require a significant investment in equipment (Ref 1$)$.

Additionally, for heat exchangers with fins, the optimal geometry to reduce manufacturing costs and concerns does not necessarily correspond to the ideal geometry for thermal performance. The fin geometry has a significant effect on fin efficiency. Indeed, increasing the height to cross-section area ratio can dramatically lower the fin efficiency, thus yielding a lower overall heat exchanger thermal performance. Furthermore, fin efficiency is also dependent on the fin material thermal conductivity. For low service temperature applications (less than $200{ }^{\circ} \mathrm{C}$ ), materials having a high thermal conductivity such as copper or aluminum can be used. For higher service temperature $\left(600{ }^{\circ} \mathrm{C}\right)$ or highly corrosive environments, 


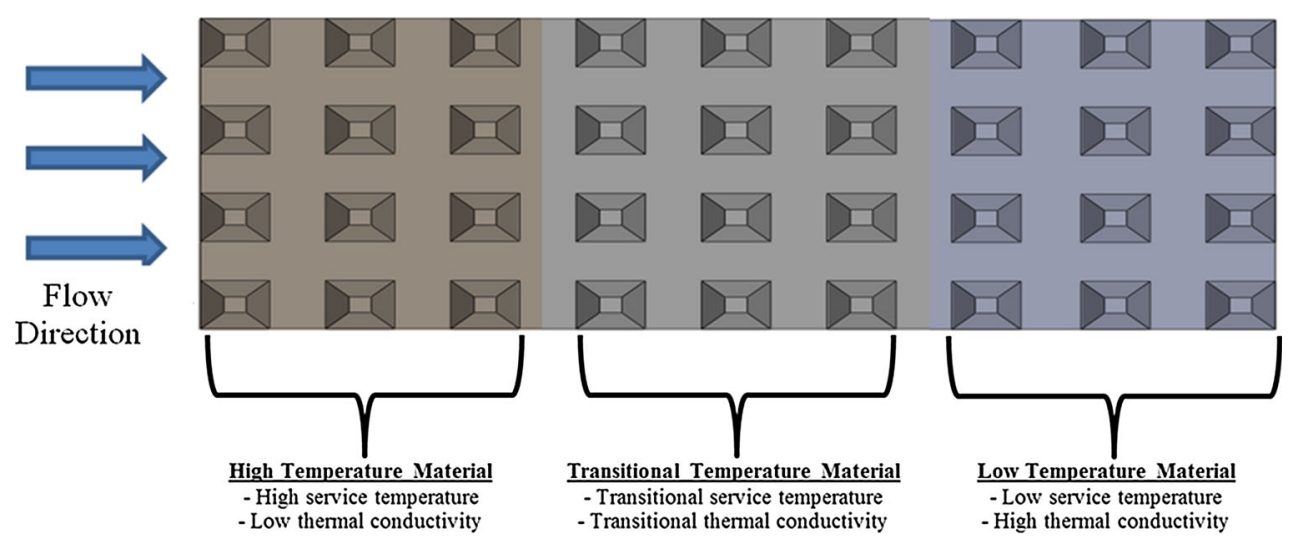

Fig. 1 Schematic of a multi-material fin array separated into three sections

materials such as nickel-based alloys or stainless steel must be used. These materials suffer from the drawbacks of having lower thermal conductivities and are usually denser than the aforementioned materials, leading to fin arrays with lower thermal performance per unit mass (Ref 9). The thermal performance is further decreased when high convective coefficients are present, which makes the design of high service temperature heat exchangers using pin fin arrays a challenge (Ref 10,11).

Another limitation of conventional fin array manufacturing methods is that they typically restrict a fin array to sections made of one homogeneous material. These sections can be joined together to create mixed material fin arrays, but this rapidly becomes uneconomical or impractical due to reliability issues with the bond between the sections. Additionally, the bonding agent itself represents a thermal barrier for the heat flow. This type of process is usually limited to plain rectangular fin geometries due to manufacturing concerns (Ref 5).

A new method for producing near-net-shaped pin fin arrays has been proposed, which uses Cold Gas Dynamic Spraying (CGDS) and a mask to selectively deposit material onto a substrate $(\operatorname{Ref} 12,13)$. The adhesion of the particles to the substrate is attributed to the large plastic deformation of the particle and substrate upon impact, which yields intimate metal to metal contact, where metallic bonds and mechanical anchoring occur (Ref 14, 15). CGDS is especially well suited for the near-netshaped production of fin arrays using substrate masking due to the low process temperatures preventing melting during the deposition process. These advantages allow for the process to be used effectively, without significant clogging, distortion, or degradation of the metallic mask.

The pin fins produced with the masked cold spray technique have a square-based pyramidal structure, with the fin density varying between 12 and 24 fins per inch and the height varying between 1.0 and $2.5 \mathrm{~mm}$. The hydrodynamic and thermal performance of this type of fin array has also been studied and was found to be superior to similar size continuous fins (plain rectangular fins) (Ref 12, 13, 16). The mechanical properties of fin arrays produced using CGDS were also determined to ensure that the stresses arising from the drag due to fluid flow could be sustained by these features without failure (Ref 17).

Since it has been proven that using CGDS as an additive manufacturing process to produce pyramidal pin fins can yield arrays with enhanced thermal properties, attention is now given to the exploration of the different materials that could be used for manufacturing this type of fin array. In this work, the thermal performances of aluminum, stainless steel 304, and nickel fin arrays are investigated. The possibility of creating multi-material heat exchangers would allow the designer the freedom of using the material combination which not only maximizes the thermal performance, but also allows for the substitution of high cost, heavy alloys by lighter and cheaper materials in the lower service temperature sections of the heat exchanger. The heat exchanger could be separated into three sections: a lower, an intermediate, and a high service temperature sections (Fig. 1) since a transfer of energy occurs between the fins and the fluid, resulting in a decrease of local fluid temperature along the length of the heat exchanger, as seen in a typical cooling curve of temperature as a function of distance (Fig. 2). The procedure for the production of this type of hybrid material fin array using the masked CGDS process is detailed, and its thermal performance is investigated.

\section{Fin Array Production}

\subsection{Feedstock Powders}

Pure commercially available aluminum $(99.8 \% \mathrm{Al}$, CenterLine (Windsor) Limited, Windsor, ON, Canada) was used. The powder size is characterized by a D10 value of 13.29 microns, a D50 value of 25.35 microns, and a D90 value of 49.58 microns, as measured using a laser diffraction analysis apparatus (Microtrac model S3500, Montgomeryville, PA, USA). The powder presents an elongated, non-spherical geometry, as seen in Fig. 3(a).

The second powder used was a commercially pure nickel powder (99.9\%, Atlantic Equipment Engineers, Upper Saddle River, NJ, USA). The powder size is characterized 


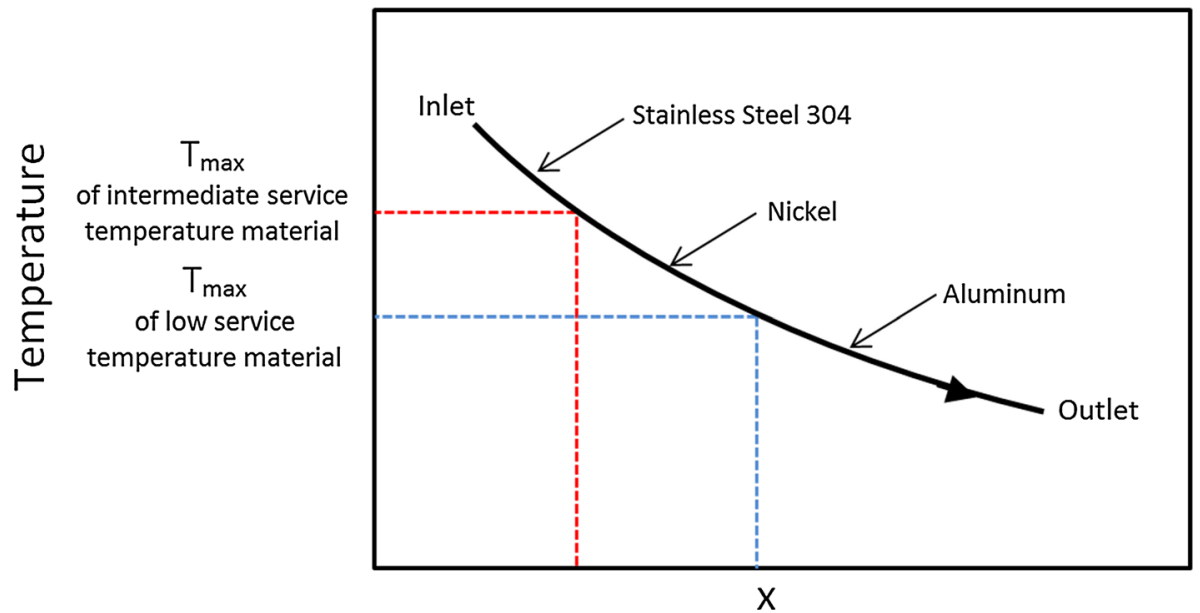

Fig. 2 Typical cooling curve of temperature as a function of distance
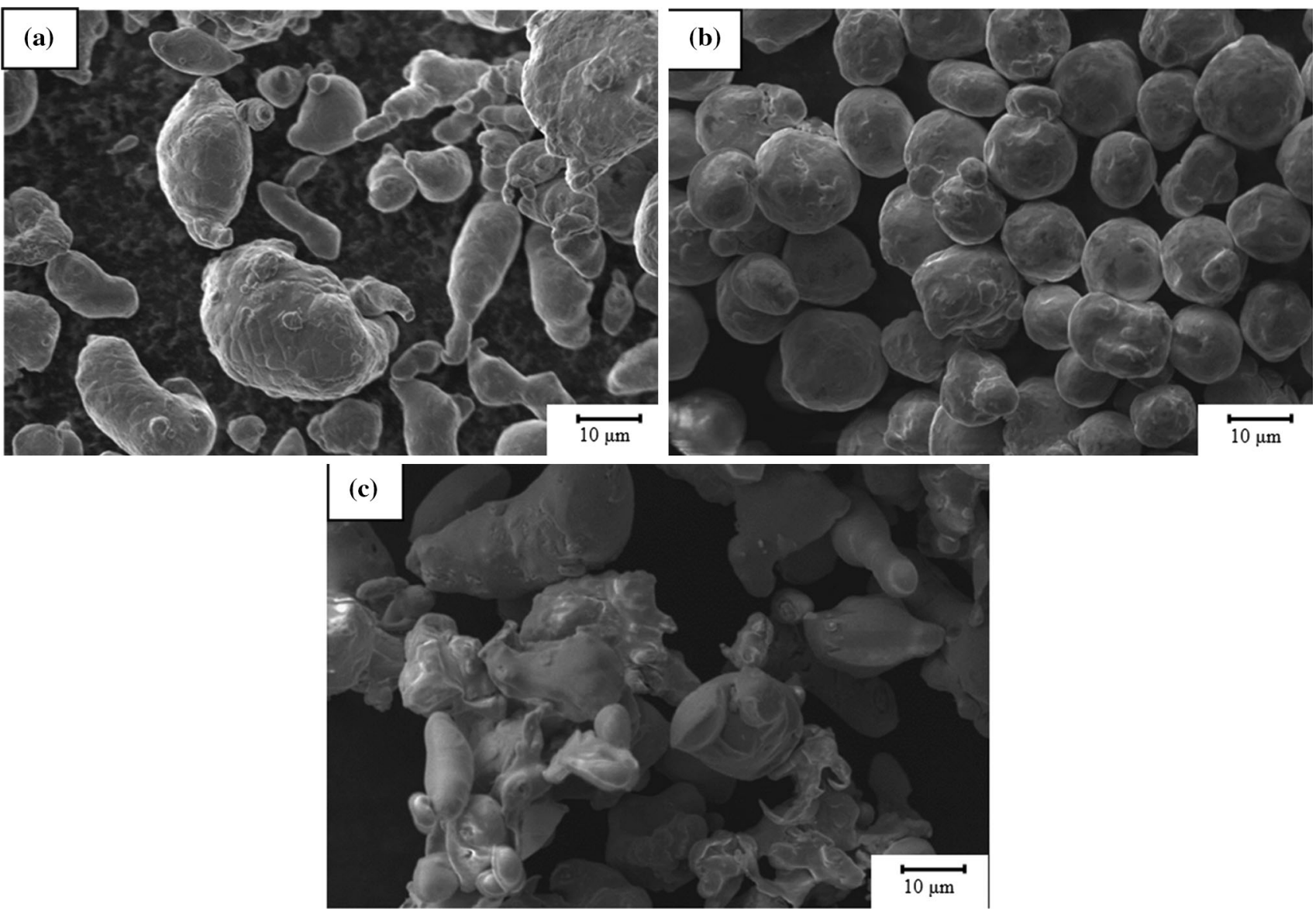

Fig. 3 SEM images of (a) As-received pure aluminum feedstock powder; (b) As-received pure nickel feedstock powder; (c) As-received stainless steel 304 feedstock powder

by a D10 value of 12.77 microns, a D50 value of 22.34 microns, and a D90 value of 40.44 microns. The powder presents a spherical geometry, as seen in Fig. 3(b).
The third feedstock powder used was a grade 304 stainless steel (Atlantic Equipment Engineers, Upper Saddle River, NJ, USA). The powder size is characterized 


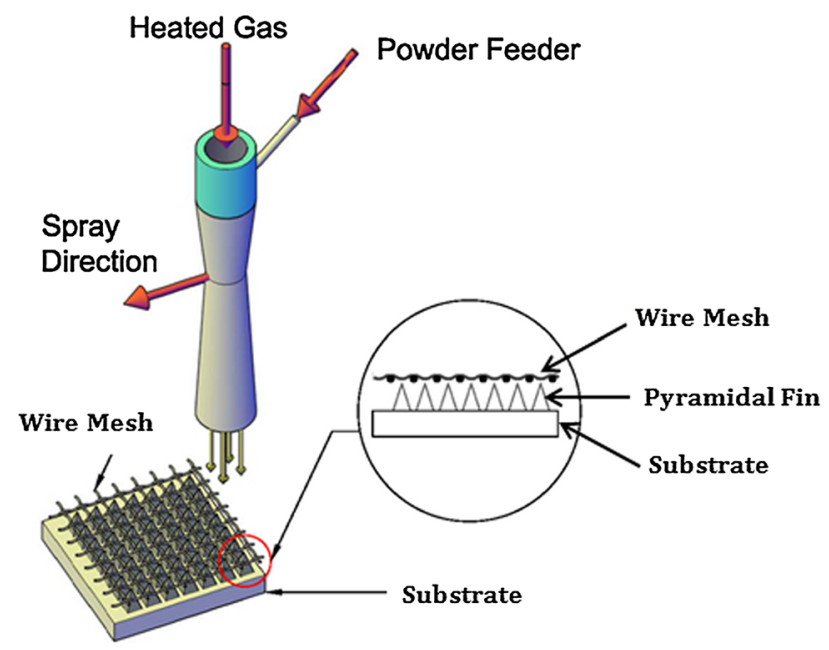

Fig. 4 Schematic of the manufacturing technique utilized to produce pyramidal fin arrays (Ref 17)

Table 1 Fin array spray parameters

\begin{tabular}{lcccc}
\hline Powder type & $\begin{array}{c}\text { Nozzle inlet pressure, } \\
\mathbf{M P a}\end{array}$ & $\begin{array}{c}\text { Nozzle inlet gas temperature, } \\
{ }^{\circ} \mathbf{C}\end{array}$ & $\begin{array}{c}\text { Powder preheating temperature, } \\
{ }^{\circ} \mathbf{C}\end{array}$ & $\begin{array}{c}\text { Standoff distance, } \\
\mathbf{m m}\end{array}$ \\
\hline Pure aluminum & 1.7 & 350 & N/A & 15 \\
Pure nickel & 2.8 & 400 & 300 & 15 \\
Stainless steel 304 & 3.1 & 475 & 300 & 15 \\
\hline
\end{tabular}

by a D10 value of 13.50 microns, a D50 value of 29.61 microns, and a D90 value of 51.66 microns. The powder presents an elongated, non-spherical geometry, as seen in Fig. 3(c).

\subsection{CGDS Fin Production Technique}

The manufacturing method used to create the squarebased pyramidal pin fin arrays using CGDS is illustrated in Fig. 4. It consists of using plain woven, steel wire mesh (McMaster-Carr, Aurora, OH, USA) to mask parts of the substrate from deposition of the particles accelerated by the cold spray process. This allows the user to build features of various shapes and dimensions on the substrate. The operating principles of CGDS result in preferential build-up of material in the center of the mask openings, creating features with reducing cross sections along the height such as pyramids (Ref 12). The CGDS deposition parameters are selected to ensure that the features closely mimic the reversed geometry of the chosen wire mesh, with peaks aligning with the holes of the screened area. Additional details on the production of pyramidal pin fins can be found elsewhere (Ref 12,13). The wire mesh mask chosen for this study has 12 wires per inch with a wire diameter of $0.035 "(0.89 \mathrm{~mm})$ in both the longitudinal and transverse directions.

An SST-EP CGDS system (CenterLine (Windsor) Limited, Windsor, ON, Canada) was used to produce the pyramidal fin arrays. A polymer nozzle was used to spray the pure aluminum powder, while a tungsten-carbide nozzle was used to deposit both the nickel and the stainless steel powders. Both nozzles have a $2.0-\mathrm{mm}$ throat diameter and a 6.4-mm exit diameter. The spray parameters used to deposit the fins for each feedstock powder are presented in Table 1 . The fins were deposited on $5.1 \mathrm{~cm}$ by $5.1 \mathrm{~cm}$ Al6061-T6 aluminum alloy substrates which were cleaned and degreased using acetone after being cut to size. The fins were sprayed taller than the desired height, and were subsequently ground down to size to ensure production consistency, using the procedure described in Dupuis et al. (Ref 13).

Samples have been produced with three different fin materials as well as a single fin material on a single fin array to demonstrate the possibility and the viability of creating this type array by additive manufacturing using cold spray. For the multi-material sample, since the sample is two inches long with 12 fins per inch, the fin array was divided into three sections of eight fins each. The stainless steel fins were deposited on the leading edge of the sample, while the aluminum was deposited on the trailing edge of the sample, with the nickel section separating the other two sections (in the order of their maximum service temperature). This does not represent the optimal ratio but rather serves as a proof of concept for this type of application. 


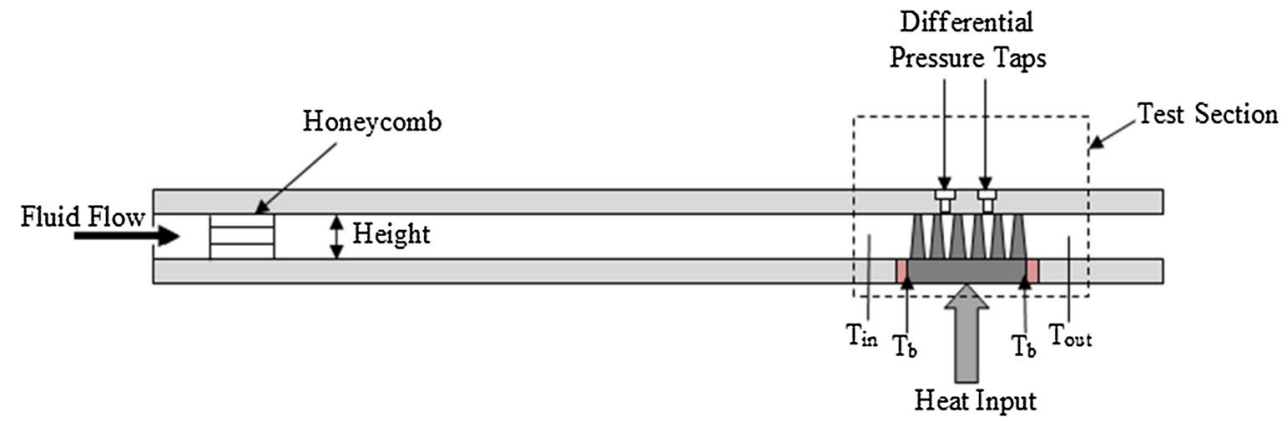

Fig. 5 Heat transfer fixture utilized to evaluate the fin arrays heat transfer performance

\section{Experimental Procedure}

\subsection{Sample Surface and Fin Characterization}

Standard metallographic procedures were used to obtain cross sections of the sprayed samples. Control specimens were sprayed to obtain a standard for comparison and to establish a porosity level baseline for the different fin materials. Image analysis was performed using Clemex Vision Lite (Clemex Technologies Inc., Longueuil, QC, Canada) image analysis software. The porosity values are reported using the mean of 10 measurements for each dataset.

The fin array geometric variables such as base dimensions and height were measured using a depth of field microscope (Keyence model VHX-2000, Mississauga, ON, Canada) which allows building three-dimensional images of the given samples. From these dimensions, the fin base angle, the hydraulic diameter, and the total heat transfer area were computed.

The heat transfer area surface roughness was also characterized using the same depth of field microscope in a two-step approach. The first step was to obtain the roughness profile of the heat transfer passage base (between the fins), using the conventional method of depth of field microscopy. In the second step, the roughness of the fins surface was obtained by tilting the microscope to the angle matching the base angle of the pyramid to obtain a perpendicular view of the fin surface. A two-dimensional correction algorithm was used to linearly correct the slope of the sample in a plane, and the roughness data were generated directly from the input image file. The total roughness was then determined to be equal to an area weighted average of the roughness of the entire flow passage.

\subsection{CGDS Coating Thermal Conductivity Determination}

A laser flash diffusivity testing apparatus (DLF-1300, TA Instruments, New Castle, DE, USA) was used to determine the room temperature thermal diffusivity and the specific heat capacity of 12.7-mm-diameter samples produced by cold spray at room temperature. The thermal conductivity of the sprayed samples was determined using the definition of the thermal diffusivity:

$\alpha=\frac{k}{\rho_{\mathrm{m}} \cdot C_{\mathrm{pm}}}$,

where $\alpha$ is the thermal diffusivity of the material, $k$ is its thermal conductivity, $\rho_{\mathrm{m}}$ is its density, and $C_{\mathrm{pm}}$ is its specific heat capacity. The samples were weighed, and the volume was measured by water volume displacement to obtain the coating density.

\subsection{Fin Thermal Performance Testing}

3.3.1 Apparatus and Test Procedure. Performance of the various fin arrays produced was assessed using an in-house heat transfer and pressure drop test apparatus. A schematic of the apparatus is shown in Fig. 5. The main components of this system are the air supply, the test section, the heating pad, and the data acquisition system. The air is supplied by a compressed air line equipped with a filter and dehumidifier. The air inlet flow rate is controlled by a needle valve and is measured with a flow meter. This air is smoothly expanded into a horizontal rectangular channel with a diffuser and a honeycomb flow straightener. An unobstructed 457-mm-long rectangular channel ensures that the flow is fully developed before reaching the test section. The test sample is subjected to a constant heat flux provided by a strip heater.

A set of differential pressure measurement taps is spaced $12.7 \mathrm{~mm}$ upstream and downstream from the middle of the test section along the centerline of the apparatus to determine the fin array friction losses. The fin array friction losses include contributions from both skin friction and form drag. A thermocouple is located $6.0 \mathrm{~mm}$ ahead of the test section and another $6.0 \mathrm{~mm}$ after the test section at mid-height to record the local average temperature of the fluid. Four thermocouples are attached to the fin array's base, with two on the side facing the incoming flow, and two on the side facing the exiting flow. On each face, a thermocouple is located on the centerline, while the other thermocouple is located $6.0 \mathrm{~mm}$ away from the wall. All the thermocouples used are T-type, butt-bonded, 28 gage thermocouples. 
All measurements were performed at steady-state and were repeated until statistical significance was achieved. Heat transfer data samples were taken at $2 \mathrm{~Hz}$ over a $30 \mathrm{~s}$ interval. For both thermal and hydrodynamic tests, five sets of data samples were recorded for each flow rate. Measurements were taken at air flow rates of 10-70 SLPM, which corresponds to Reynolds numbers varying from 400 to 3000 , which are in the laminar and the subcritical flow regimes. Deviation of the measurements from the mean value was less than $5 \%$, which led to error bars that were smaller than the markers. For this reason, they were not included in the thermal performance graphs of "Results" section. A detailed description of the apparatus' accuracy and of the instrument's uncertainties is given in Cormier et al. (Ref 12). Radiative heat transfer losses are neglected as they would account for less than $0.5 \%$ of the total heat input $(\operatorname{Ref} 18,19)$.

3.3.2 Data Reduction. The thermal performance comparison is done according to the procedure detailed in Sahiti's work (Ref 20). This method relates the thermal and hydrodynamic data by plotting the thermal conductance as a function of the required pumping power for a unit volume of heat exchanger at different flow rates. This yields performance curves which can be directly compared one to another, with the most efficient fin array having a higher thermal conductance at a given pumping power.

The equivalent thermal conductance per unit volume for the heat exchanger specimen can be calculated using

$\mathrm{UA}=\frac{1}{R_{\mathrm{eq}}}=\frac{q}{\Delta T_{\mathrm{lm}}}$,

where $R_{\mathrm{eq}}$ is the thermal circuit's equivalent resistance, $q$ is the total heat input rate to the system, and $\Delta T_{\mathrm{lm}}$ is the log-mean temperature difference between the fluid and the fin array. The thermal conductance is either normalized using the volume of the heat transfer extended surface $\left(V\right.$, yielding $\left.\mathrm{UA}_{\mathrm{v}}\right)$ or using the mass of this extended surface $\left(M\right.$, yielding $\left.\mathrm{UA}_{\mathrm{M}}\right)$.

The total heat input rate to the system is calculated using

$q=\dot{m} \cdot\left(T_{\text {out }}-T_{\text {in }}\right) \Delta C_{\mathrm{pf}}$,

where $\dot{m}$ is the fluid mass flow rate, $\left(T_{\text {out }}-T_{\text {in }}\right)$ is the fluid temperature difference between the entrance and the exit of the test section, and $C_{\mathrm{pf}}$ is the fluid's thermal capacitance.

The log-mean temperature difference is calculated with

$\Delta T_{\operatorname{lm}}=\frac{\Delta T_{1}-\Delta T_{2}}{\ln \left(\frac{\Delta T_{1}}{\Delta T_{2}}\right)}$,

where $\Delta T_{1}$ and $\Delta T_{2}$ are the temperature differences between the fin surface and the flow at the inlet and outlet, respectively.

The thermal resistance of a fin array can be computed with the following relation:
$R_{\mathrm{eq}}=\frac{1}{h \cdot A_{t} \cdot \eta_{o}}$.

(Eq 5)

In the previous equation, $h$ is the average convective coefficient, $A_{\mathrm{t}}$ is the total heat transfer area of the fin array and the base, while $\eta_{\mathrm{o}}$ is the total surface efficiency, defined as the actual heat transfer rate over the maximal heat transfer rate that can be transferred if the surface temperature is uniform and equal to the base temperature. This parameter can be calculated as follows:

$\eta_{\mathrm{o}}=1-\frac{A_{\mathrm{f}}}{A_{\mathrm{t}}}\left(1-\eta_{\mathrm{f}}\right)$,

where $A_{\mathrm{f}}$ is the finned area and $\eta_{\mathrm{f}}$ is the individual fin efficiency, defined as the heat transferred by the fins over the maximum possible heat that can be transferred, which can be approximated with

$\eta_{\mathrm{f}}=\frac{2}{m H} \frac{I_{2}(2 m H)}{I_{1}(2 m H)}$

and

$m=\sqrt{\frac{4 h}{k D}}$.

In the previous equations adapted from Incropera's work (Ref 11). $H$ denotes the height of fin (or length of protrusion of the fin from the base), $I_{1}$ and $I_{2}$ denote the first- and second-order Bessel functions, respectively, while $k$ is the thermal conductivity of the fin's metal. For the particular fin geometry used in this work, $D$ corresponds to the fin base length $(B)$.

The required pumping power input was calculated according to Sahiti's definition (Ref 21):

$e=\frac{\dot{V}_{\mathrm{f}} \cdot \Delta P_{\text {fin }}}{\eta}$.

In the previous relation, $e$ is the pumping power, $\dot{V}_{\mathrm{f}}$ is the volumetric flow rate of the fluid, $\Delta P_{\text {fin }}$ is the pressure drop measured, and $\eta$ is the fan efficiency. A fan efficiency of 0.8 was chosen as a reasonable value to perform these calculations (Ref 21). This pumping power is either normalized using the volume of the heat transfer extended surface $\left(V\right.$, yielding $\left.e_{v}\right)$ or using the mass of this extended surface ( $M$, yielding $e_{M}$ ).

For these experiments, the Reynolds number $(R e)$ of the flow is defined as

$R e_{\mathrm{Dh}}=\frac{\rho_{\mathrm{f}} \cdot U \cdot D_{\mathrm{h}}}{\mu}$,

where $\rho_{\mathrm{f}}$ is the fluid's density, $U$ is the free-stream axial velocity, $D_{\mathrm{h}}$ is the hydraulic diameter of the flow channel, and $\mu$ is the dynamic viscosity of the working fluid.

The average roughness of the heat exchanger samples $\left(R a_{\mathrm{A}}\right)$ was determined using an area weighted average of the wetted surfaces' roughness:

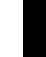



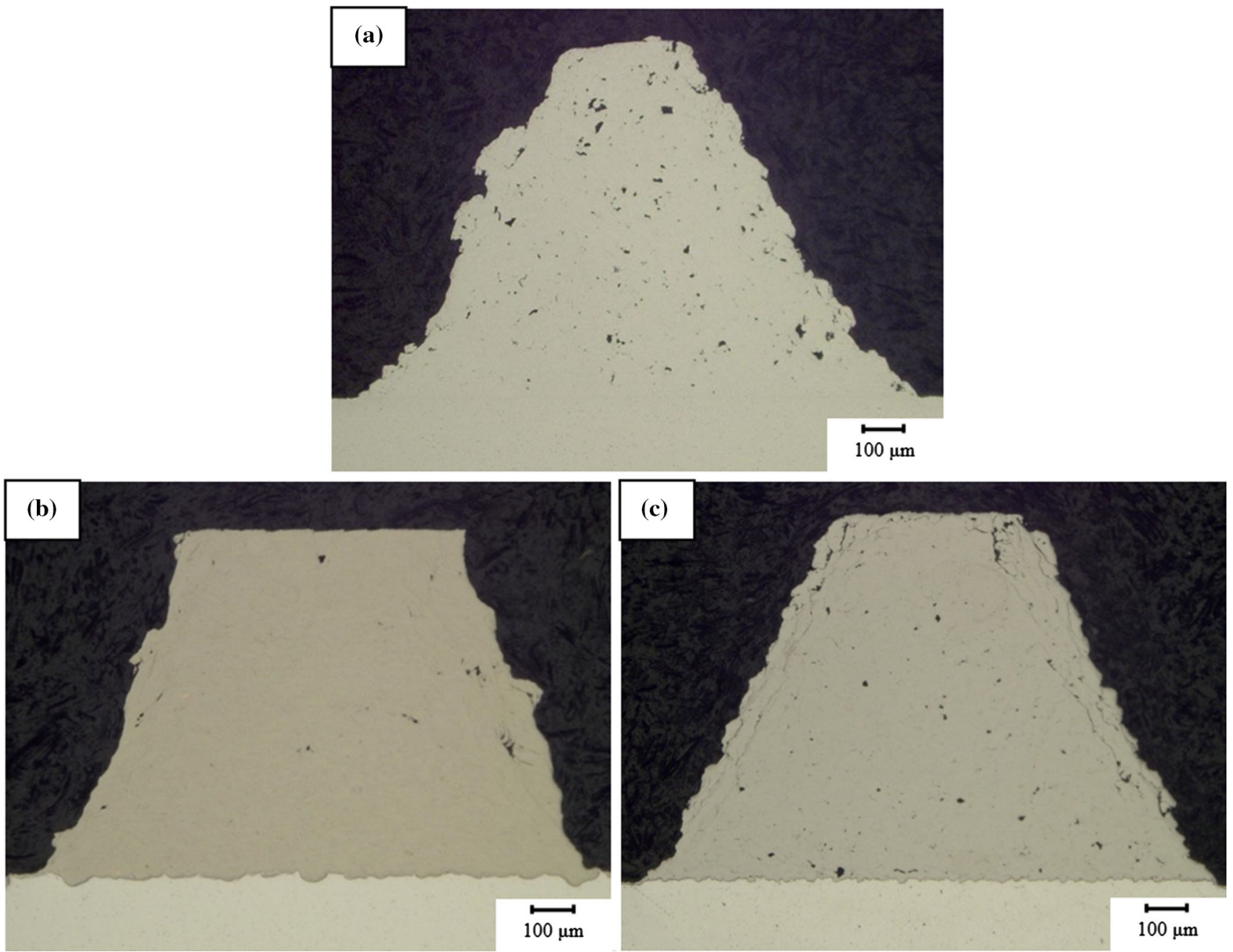

Fig. 6 Cross section of different type of pyramidal fin produced (a) Pure aluminum; (b) Pure nickel; (c) Stainless steel 304

$R a_{\mathrm{A}}=\frac{R a_{\mathrm{f}} A_{\mathrm{f}}+R a_{\mathrm{b}} A_{\mathrm{b}}}{A_{\mathrm{t}}}$,

where $R a_{\mathrm{f}}$ is the roughness value of the fin's surface, $R a_{\mathrm{b}}$ is the roughness of the unfinned base, and $A_{\mathrm{b}}$ is the unfinned base area. The roughness of the shroud material is not considered in this equation, as its roughness is negligible when compared to that of either the base or the fin surface.

\section{Results}

The different types of samples were characterized, with typical cross sections shown in Fig. 6 and the important geometric quantities associated with the different samples presented in Table 2. This figure shows similar shaped fins for the different samples, with some differences in the top length of the fins, attributed to over-grinding of the specimens during sample preparation, leading to cross sections that are not exactly at the center of the fin depicted in the figure.

Figure 7 presents the thermal conductance as a function of Reynolds number for the different samples tested. Observing this figure, the data that stand out are the thermal performance of the nickel and multi-material samples, which have a significantly higher thermal conductance than the other samples at a given Reynolds number.

This distribution of results is not expected when looking at the thermal conductivities of the fin array materials: pure aluminum has the highest thermal conductivity, with a theoretical value of $237 \mathrm{~W} / \mathrm{m} \mathrm{K}$, followed by nickel with an intermediate value of $91 \mathrm{~W} / \mathrm{m} \mathrm{K}$, and finally stainless steel 304 with the lowest value of $15 \mathrm{~W} / \mathrm{m} \mathrm{K}$ (Ref 11). Solely looking at the thermal conductivity, however, gives an incomplete analysis of the data presented in Fig. 7, as it would then be expected that the aluminum sample would outperform the nickel sample. The comparable 
Table 2 Important variables of pyramidal fin array

\begin{tabular}{|c|c|c|c|c|c|c|c|}
\hline Sample name & Fin material & $\underset{\mu \mathrm{m}}{\text { Fin height }}(\mathbf{H})$, & $\begin{array}{c}\text { Base (B), } \\
\mu \mathrm{m}\end{array}$ & $\begin{array}{c}\text { Total heat transfer } \\
\text { area, } \mathbf{m m}^{2}\end{array}$ & $\begin{array}{l}\text { Hydraulic diameter, } \\
\text { mm }\end{array}$ & Base angle, ${ }^{\circ}$ & Porosity, \% \\
\hline Aluminum & Pure aluminum & $1048 \pm 12$ & $1401 \pm 30$ & $3775 \pm 72$ & $1103 \pm 40$ & $62.4 \pm 1.0$ & $2.8 \pm 1.5$ \\
\hline Nickel & Pure nickel & $974 \pm 35$ & $1352 \pm 28$ & $3612 \pm 66$ & $1045 \pm 54$ & $62.5 \pm 1.7$ & $0.8 \pm 0.6$ \\
\hline Stainless steel 304 & Stainless steel 304 & $1019 \pm 42$ & $1351 \pm 69$ & $3687 \pm 160$ & $1081 \pm 92$ & $62.1 \pm 1.6$ & $1.1 \pm 0.6$ \\
\hline Multi-material & $\mathrm{Al} / \mathrm{Ni} / \mathrm{SS}$ & $1008 \pm 52$ & $1372 \pm 64$ & $3903 \pm 164$ & $1062 \pm 92$ & $64.8 \pm 2.6$ & $1.5 \pm 1.3$ \\
\hline
\end{tabular}

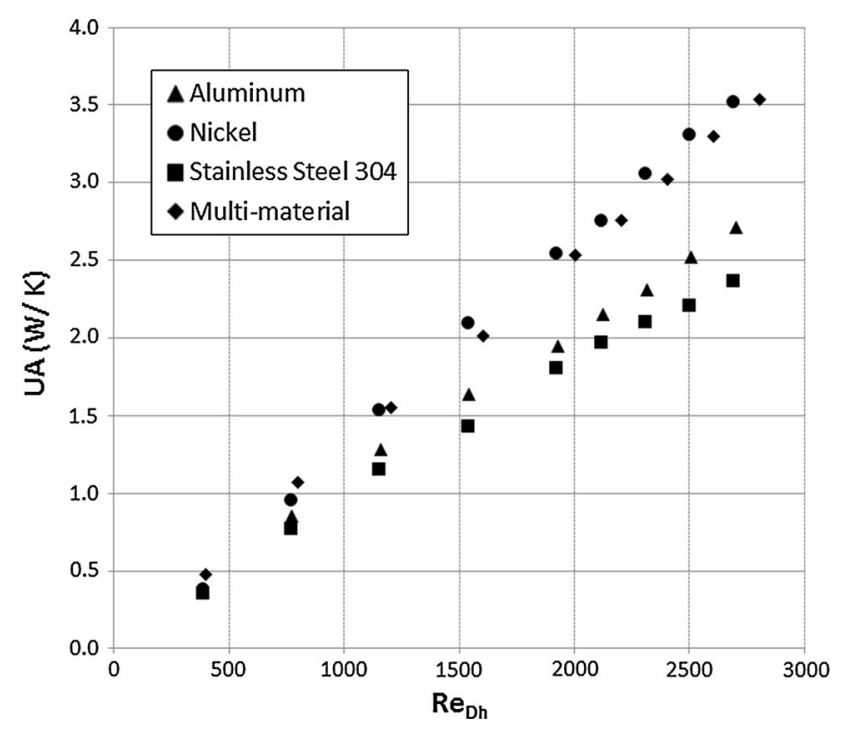

Fig. 7 Thermal conductance comparison between aluminum (triangle), nickel (circle), stainless steel 304 (square), and multimaterial (diamond)

performance of these samples can then be partially explained by looking at the definition of the equivalent thermal resistance for fin arrays. Since the fin arrays have very similar geometries and are compared at the same flow conditions, it follows that the convective coefficient and the total heat transfer area are similar between samples tested at the same flow conditions. The only parameter that can vary significantly is then the total surface efficiency, which is itself dependent on the fin efficiency. Considering Eq 6, 7, and 8, the effect of the fin material, through its thermal conductivity, can be seen. For convenience, the results of Eq 6 are plotted as a function of the convective coefficient for different fin material conductivity values and are presented in Fig. 8. It should be noted that the fin efficiency is high due to their dimensions (low height to cross-section area ratio). This chart demonstrates that there is a negligible performance loss when going from bulk aluminum to bulk nickel (237-91 W/m K) with less than $0.4 \%$ for convective coefficient values of $800 \mathrm{~W} /$ $\mathrm{m}^{2} \mathrm{~K}$, but there is a more significant drop in the efficiency when using stainless steel $(15 \mathrm{~W} / \mathrm{m} \mathrm{K}$, a $3.0 \%$ reduction for convective coefficient values of $800 \mathrm{~W} / \mathrm{m}^{2} \mathrm{~K}$ ). However, the order of thermal conductance is not fully explained since the nickel fin array has a better thermal performance than the aluminum sample; while according to the previous explanation, their performance should be similar. Nevertheless, the lower thermal performance of stainless steel fin arrays is explained.

It has been reported that the properties of coatings produced by CGDS do not match those of the bulk material (Ref 22-25). Indeed, the mechanical, electrical, and thermal properties of a coating produced by CGDS may be widely different from the bulk, annealed material due to the large amount of plastic deformation that occurs during deposition (Ref 22). For the thermal conductivity in particular, the observed value is usually much lower than that of the bulk material due to the amount of dislocations created by the cold spray process, which shortens the mean free path for electron movement, but also due to other contributing factors such as the quality of the interparticle bonding and the presence of surface oxides in the powder, which become imbedded in the coating (Ref 22-25). The difference between the fin efficiencies for the different materials becomes even more pronounced when the real values of thermal conductivity (presented in Table 3) are used instead of values typical of bulk materials, as seen in Fig. 8. To this end, following this discussion, it would be expected that the thermal conductance curves of the different samples would be in the following order, from most performant to least performant: aluminum, followed very closely by nickel, multimaterial, and finally stainless steel.

The difference between the expected order and the order of the measured thermal conductances can then explained by looking at the hydrodynamic performance of the samples. Figure 9 presents the measured pressure losses of the fin array samples as a function of the Reynolds number. It can be observed that the nickel and multi-material samples have the highest pressure loss, followed by the stainless steel sample, with the aluminum sample having the lowest hydrodynamic losses. This trend is likely attributable to the roughness of the flow passage (the side of the fins and the substrate area between the fins). It is well known that surface roughness increases heat transfer performance and contributes significantly to pressure losses (Ref 26-28), especially in small hydraulic diameter heat exchangers (Ref 29).

A representative image of the fin's side surface is shown in Fig. 10, which results in the roughness values $\left(R a_{\mathrm{f}}\right)$ presented in Fig. 11. It is possible to observe that the nickel fin's surface is the roughest, followed by the aluminum fins and finally by the stainless steel fins. The roughness of the fin surface, on its own, cannot explain the increase in fin arrays differential pressure observed in Fig. 10 as well as the rise in the thermal conductance 


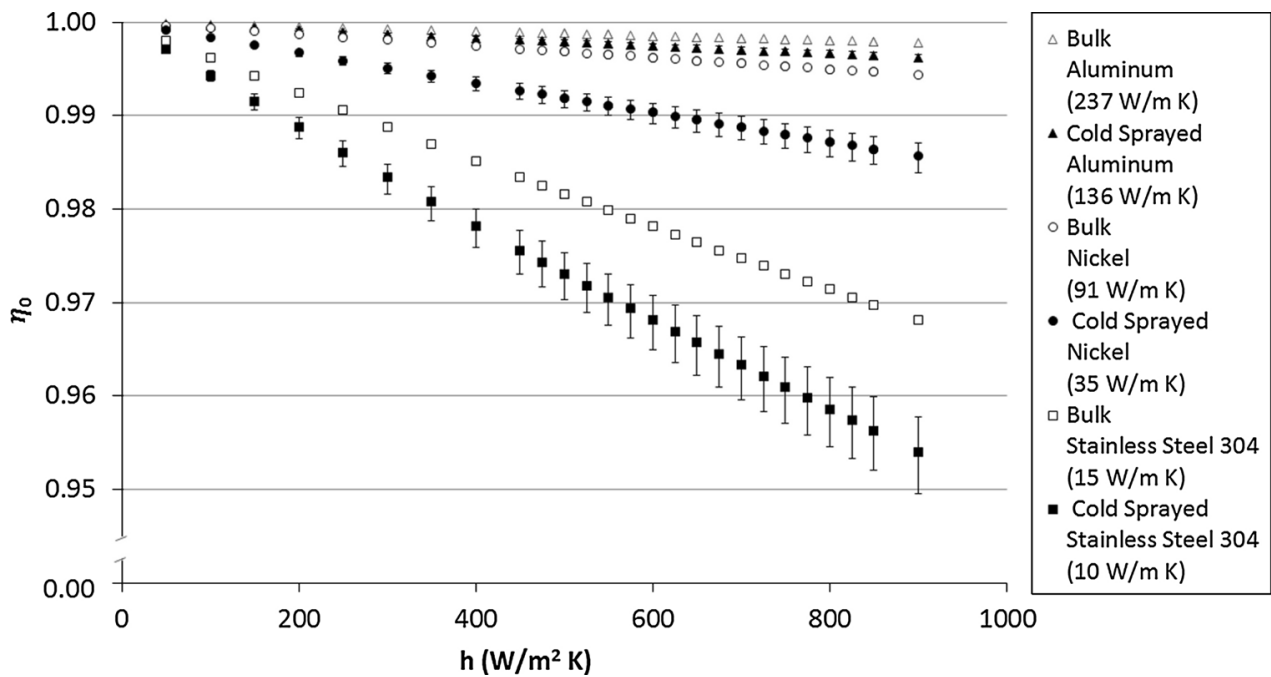

Fig. 8 Total surface fin efficiency, for the shape of the fins in the present study, in function of the convective heat transfer coefficient for different thermal conductivities

Table 3 Physical and thermal properties of the CGDS produced coatings as well as bulk thermal conductivity for comparison purpose

\begin{tabular}{|c|c|c|c|c|c|}
\hline Material & $\begin{array}{l}\text { Thermal diffusivity, } \\
\qquad \mathrm{cm}^{2} / \mathrm{s}\end{array}$ & $\begin{array}{c}\text { Thermal capacitance, } \\
\text { J/kg K }\end{array}$ & $\begin{array}{l}\text { Density, } \\
\mathbf{k g} / \mathrm{m}^{3}\end{array}$ & $\begin{array}{l}\text { Thermal conductivity, } \\
\text { W/m K }\end{array}$ & $\begin{array}{c}\text { Bulk thermal conductivity, } \\
\text { W/m K }\end{array}$ \\
\hline Pure aluminum & $0.588 \pm 0.012$ & $911 \pm 46$ & $2535 \pm 254$ & $136 \pm 15$ & 237 \\
\hline Pure nickel & $0.126 \pm 0.003$ & $341 \pm 17$ & $8137 \pm 814$ & $35 \pm 4$ & 91 \\
\hline Stainless steel 304 & $0.017 \pm 0.001$ & $882 \pm 44$ & $6988 \pm 699$ & $10 \pm 1$ & 15 \\
\hline
\end{tabular}

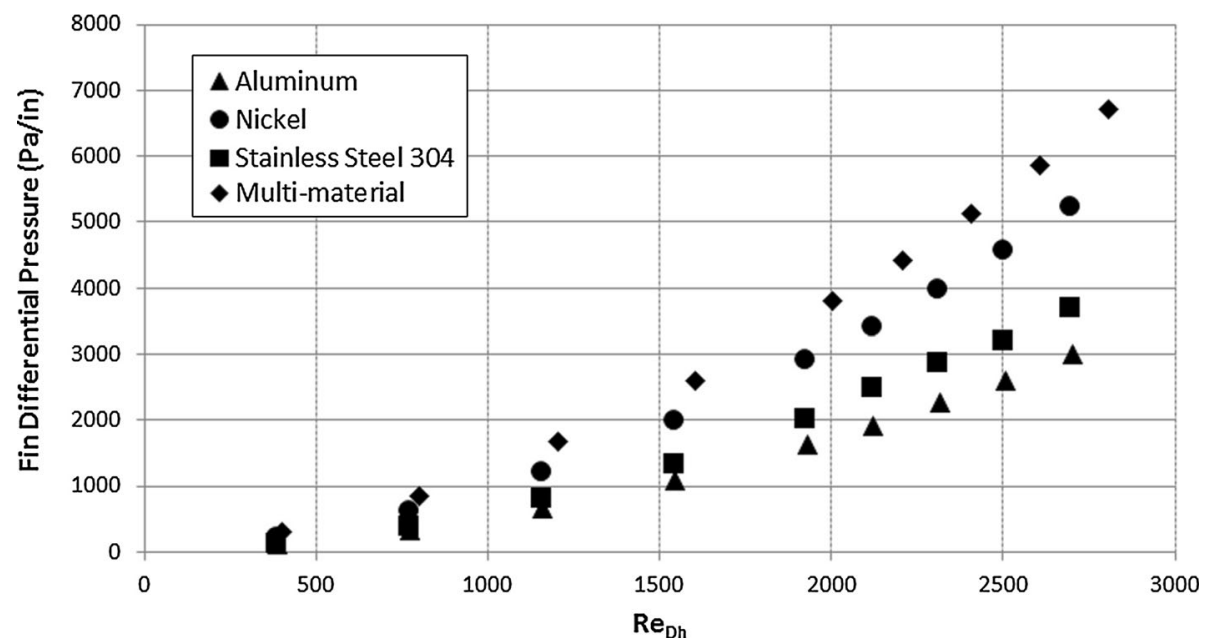

Fig. 9 Fin differential pressure per inch comparison between aluminum (triangle), nickel (circle), stainless steel 304 (square), and multimaterial (diamond)

depicted in Fig. 7 since the stainless steel sample has the lowest fin roughness, while it has a higher differential fin pressure than the aluminum. By observing the substrate area between each fin, it is possible to notice the presence of a thin layer of attached particles for the nickel and the stainless steel fin arrays (Fig. 12b and c), whereas the aluminum does not have deposition between the fins (Fig. 12a). The arithmetic mean roughness $\left(R a_{\mathrm{b}}\right)$ for the base area is shown in Fig. 11 and results in a higher roughness for the stainless steel sample followed by the nickel sample and the aluminum sample, most likely attributable to the stronger deformation of the aluminum 

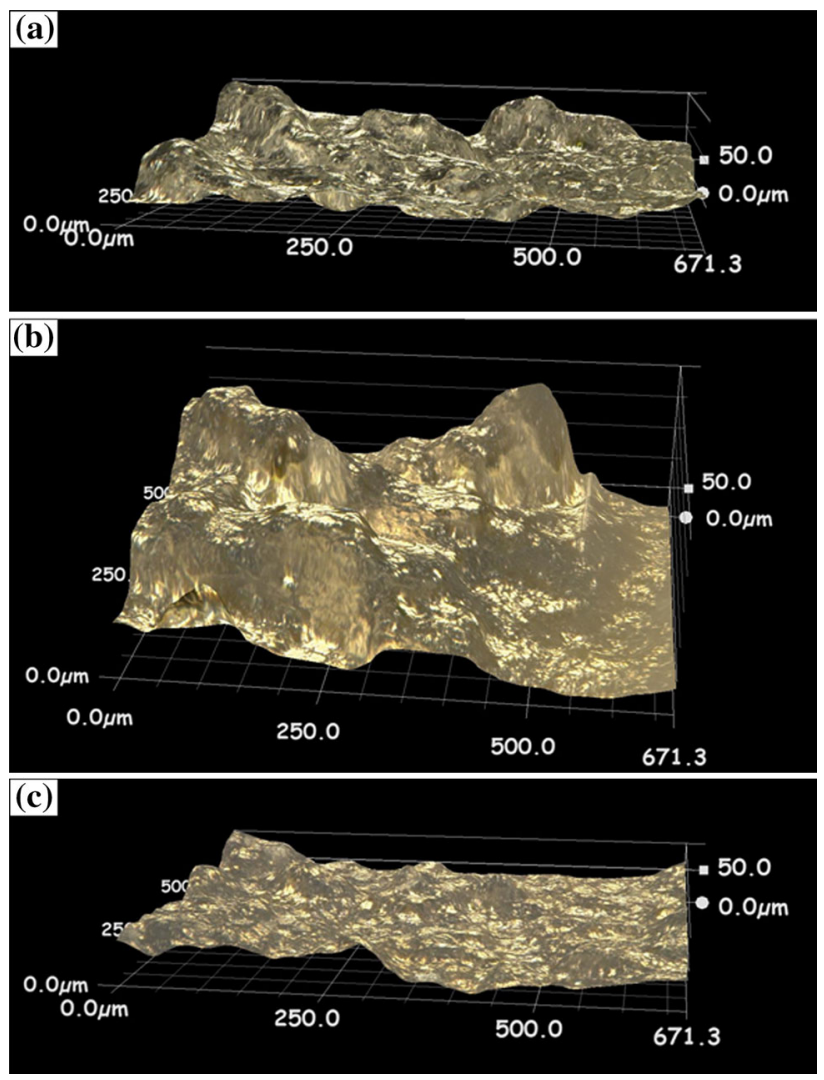

Fig. 10 Three-dimensional image of the fin's side surface for (a) Aluminum; (b) Nickel; (c) Stainless Steel 304 substrate by the heavier and harder stainless steel and nickel particles than by the softer, lighter aluminum particles. In the case of the stainless steel and nickel samples, the substrate deformation is evident, while for the aluminum, only small dimples (approximately $4 \mu \mathrm{m}$ in depth) are observed. In order to understand the performance curves, a weighted average of each component of the surface roughness (fin surface and base roughness) is computed according to Eq 11. This weighted average $\left(R a_{\mathrm{A}}\right)$ demonstrates that the nickel fin array has the highest average roughness, followed by the stainless steel and the aluminum fin arrays (Fig. 10), which correlates with the hydrodynamic performance trends observed in Fig. 9.

Using the hydrodynamic performance data and following the discussion regarding the thermal conductivity and fin efficiency, the differences in thermal performance of the samples shown in Fig. 7 can be explained. The nickel sample has the highest thermal conductance due to the increased convective coefficient (from the flow disruptions caused by to the surface roughness), despite the negligible decrease in fin efficiency associated with the use of nickel compared to aluminum. The multi-material sample's performance is similar to that of the nickel sample for the same reason, while the aluminum sample outperforms the stainless steel fin array due to its higher fin efficiency (despite the fact that they have a similar passage roughness).

The volumetric heat transfer surface efficiency curves are presented in Fig. 13. One first notes that the volumetric efficiencies of the aluminum, the nickel, and the multi-material samples are comparable, while the perfor-

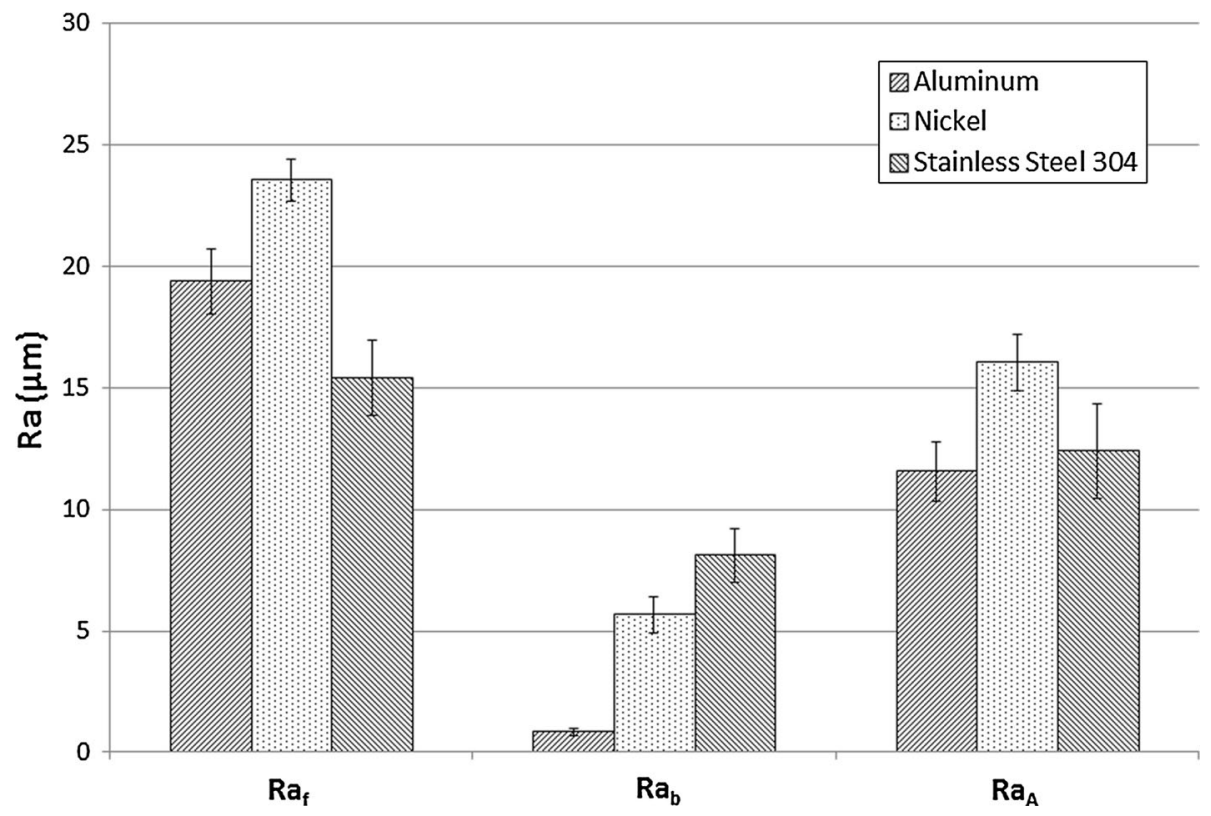

Fig. 11 Surface roughness arithmetic average for the aluminum, stainless steel 304 and nickel for (a) fin's surface; (b) Unfinned base area; (c) Total roughness 


\section{(a)}

(b)
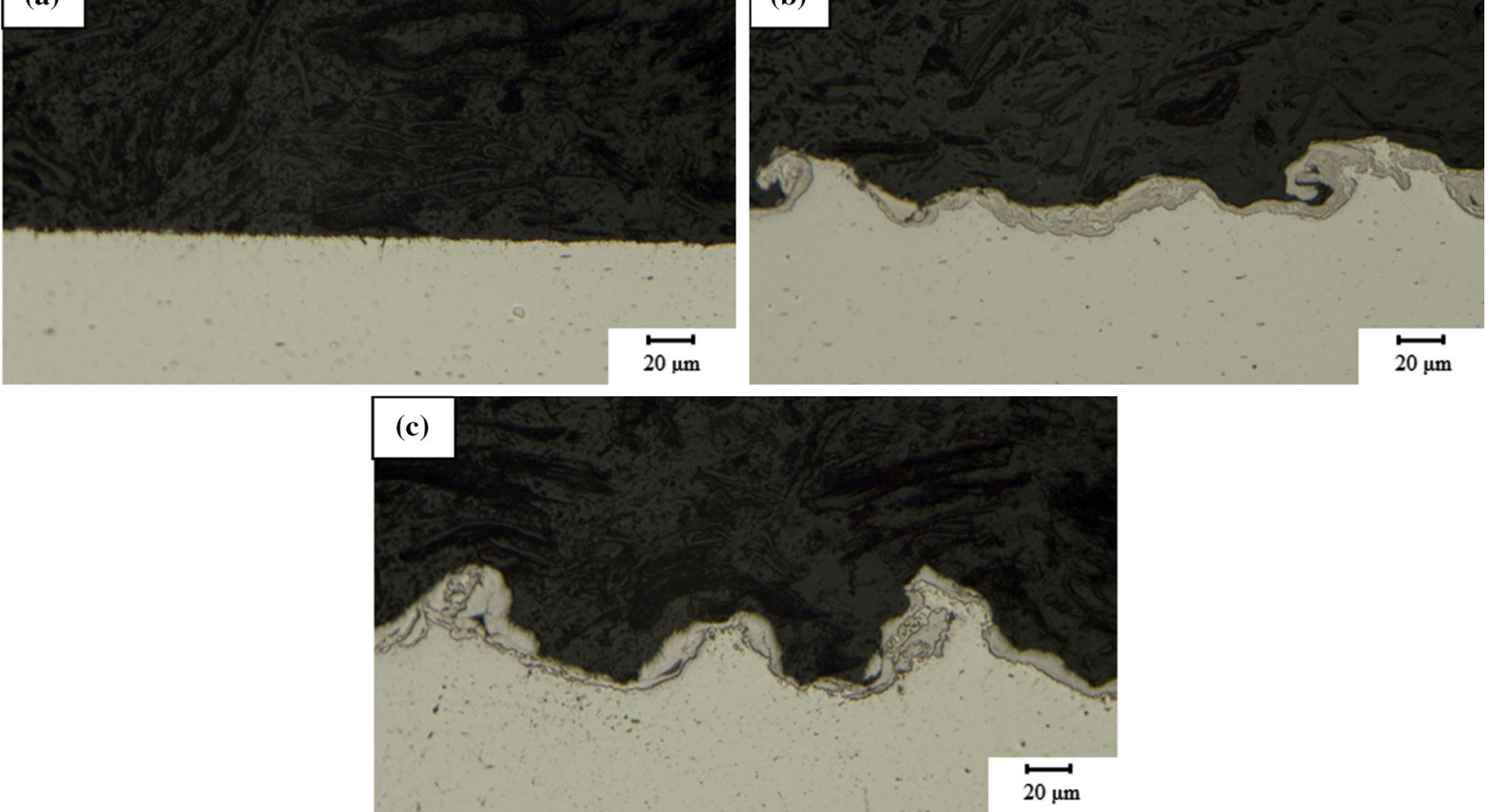

Fig. 12 Typical cross section of the unfinned surface (a) Aluminum; (b) Nickel; (c) Stainless steel 304

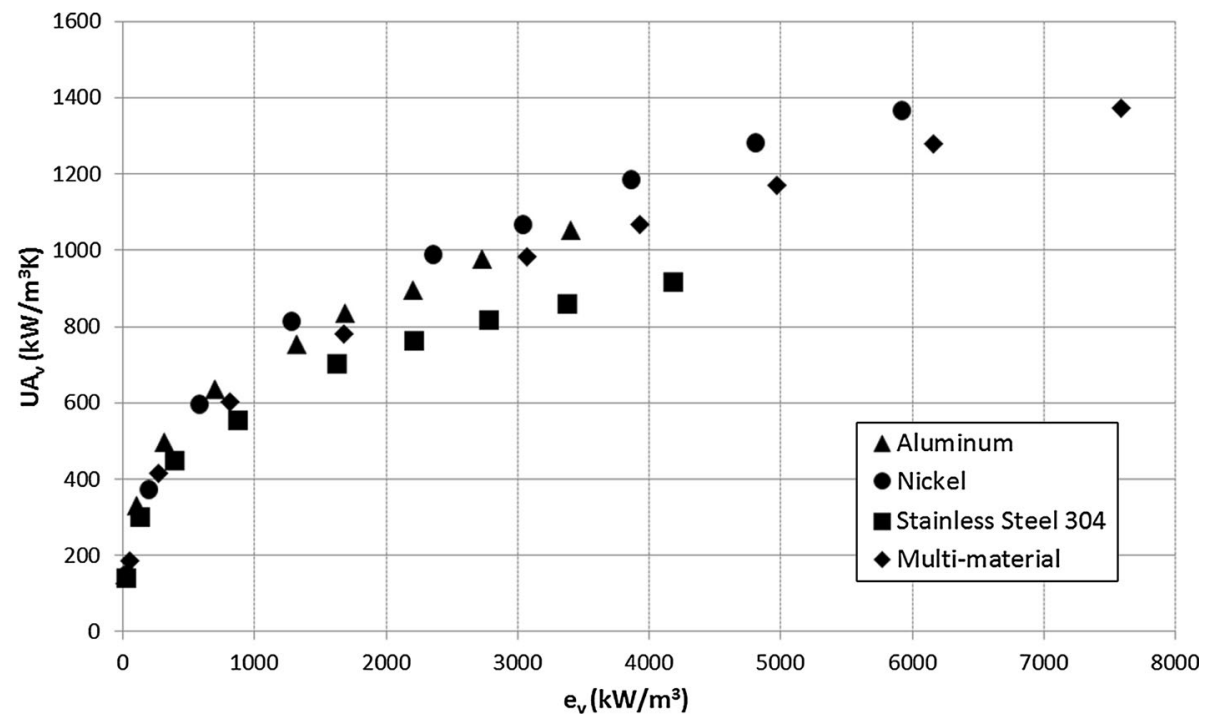

Fig. 13 Volume-based heat transfer performance comparison between aluminum (triangle), nickel (circle), stainless steel 304 (square), and Multi-material (diamond)

mance of the stainless steel sample is lower. This trend can be expected from Fig. 7 and 9, as the increased thermal performances of the multi-material and nickel samples are offset by the higher hydrodynamic losses encountered in those fin arrays. The information presented in Fig. 13, however, indicates that using a heat exchanger made of several materials with different service temperatures can yield better heat transfer performance when compared to one that uses a single-material with a high service temperature (in this example, stainless steel). This becomes 


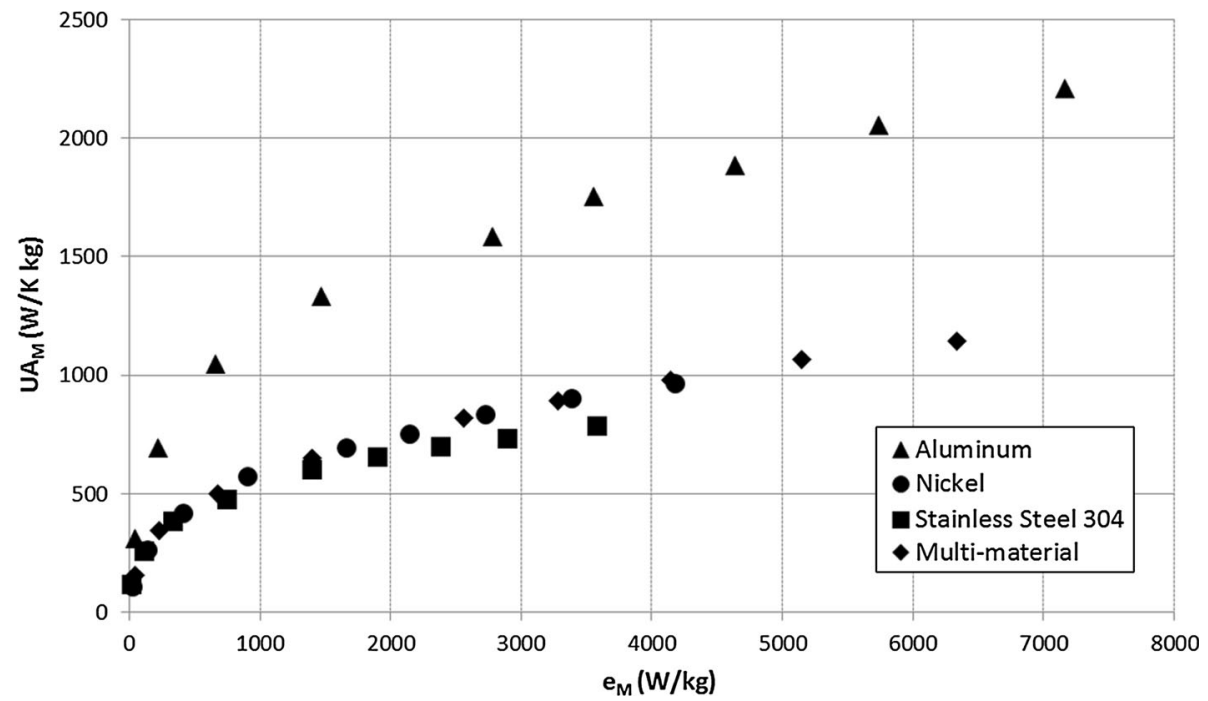

Fig. 14 Mass-based heat transfer performance comparison between aluminum (triangle), nickel (circle), stainless steel 304 (square), and multi-material (diamond)

Table 4 Summary chart of the different performance metrics between the multi-material and the stainless steel samples

\begin{tabular}{|c|c|c|c|c|}
\hline Performance metric & $\begin{array}{c}\text { Comparison } \\
\text { point }\end{array}$ & $\begin{array}{c}\text { Multi-material } \\
\text { interpolated metric } \\
\text { value }\end{array}$ & $\begin{array}{c}\text { Stainless steel } \\
\text { interpolated metric } \\
\text { value }\end{array}$ & $\begin{array}{c}\text { Metric increase of the } \\
\text { multi-material sample, } \\
\%\end{array}$ \\
\hline Figure 7 : thermal conductance & $R e_{\mathrm{Dh}}=1500$ & 1.9 & 1.4 & 35 \\
\hline (UA) $(\mathrm{W} / \mathrm{K})$ & $R e_{\mathrm{Dh}}=2500$ & 3.2 & 2.2 & 42 \\
\hline Figure 9: differential pressure & $R e_{\mathrm{Dh}}=1500$ & 2362 & 1301 & 82 \\
\hline$\left(\Delta P_{\text {fin }}\right)(\mathrm{Pa} / \mathrm{in})$ & $R e_{\mathrm{Dh}}=2500$ & 5475 & 3220 & 70 \\
\hline Figure 13: volume-based & $e_{\mathrm{v}}=1500 \mathrm{~kW} / \mathrm{m}^{3}$ & 744 & 676 & 10 \\
\hline performance $\left(\mathrm{UA}_{\mathrm{v}}\right)\left[\mathrm{kW} /\left(\mathrm{m}^{3} \mathrm{~K}\right)\right]$ & $e_{\mathrm{v}}=3000 \mathrm{~kW} / \mathrm{m}^{3}$ & 972 & 831 & 17 \\
\hline Figure 14: mass-based & $e_{\mathrm{M}}=1500 \mathrm{~W} / \mathrm{kg}$ & 666 & 611 & 9 \\
\hline performance $\left(\mathrm{UA}_{\mathrm{M}}\right)[\mathrm{W} /(\mathrm{kg} \mathrm{K})]$ & $e_{\mathrm{M}}=3000 \mathrm{~W} / \mathrm{kg}$ & 864 & 744 & 16 \\
\hline
\end{tabular}

even more apparent when the comparison is made between heat exchangers on a unit mass basis, such as the results presented in Fig. 14. In this case, aluminum becomes much more efficient than the other two materials due to its low density. Nickel, having the highest density, has its performance decreased greatly, in comparison, but is still slightly superior to that of stainless steel. The multimaterial sample once again has a similar performance to that of the nickel sample. This also confirms the viability of using a multi-material heat exchanger due to the increased performance when compared to typical single-material exchangers made of a high service temperature alloy such as stainless steel. When the service temperature does not restrict the use of low service temperature materials such as aluminum, it can be very advantageous to use this type of low-density material to increase the mass-specific thermal performance.

The tests for the multi-material sample were also performed in both orientations, with the stainless steel section closer to the inlet and then closer to the outlet, respectively. No discernable difference between the performances of the two configurations has been observed, leading to the conclusion that the efficiency of this sample is mostly attributable to the thermal and hydrodynamic performance of its nickel section. This conclusion, of course, is only applicable to the particular configuration of the multi-material fin array detailed in this work. For other configurations, the performance of the hybrid fin array will reflect that of whichever section most influences the flow physics in that particular case.

\section{Summary and Conclusion}

Near-net-shaped pyramidal fin arrays of various materials were manufactured using the CGDS process as well as a streamwise anisotropic fin array. Fin characterization was performed using conventional microscopy, as well as depth of field microscopy. Fin array performance was determined using a steady-state forced air convection apparatus. The heat transfer performance analysis has revealed that the cold spray process used to produce the fin arrays has a considerable influence on the results by modifying the fins and substrate surface roughness. Results obtained show a similar efficiency based on 
volume for the nickel, the aluminum, and the multi-material samples, while the stainless steel is less efficient. Using a unit mass criterion, the aluminum fin array outperforms the three other fin arrays. The proof of concept of using cold spray as an additive manufacturing process to produce a streamwise anisotropic fin array instead of one made from a single, high service temperature material has been performed. The performance metrics of the multimaterial sample compared to the stainless steel sample are summarized in Table 4, showing the benefits of the anisotropic approach.

\section{Acknowledgments}

Acknowledgements are due to the MITACS Accelerate Program for its financial support of this project. The authors would also like to thank Paul Jeanson and Dr. Ghazal M. Alipour of TA Instruments for the thermal conductivity values obtained by DLF.

\section{References}

1. B.A. Jasperson, Y. Jeon, K.T. Turner, F.E. Pfefferkorn, and W. $\mathrm{Qu}$, Comparison of Micro-Pin-Fin and Microchannel Heat Sinks Considering Thermal-Hydraulic Performance and Manufacturability, IEEE Trans. Compon. Packag. Technol., 2001, 33(1), p 148-160

2. S.M. Kaplan and F. Sissine, Smart Grid: Modernizing Electric Power Transmission and Distribution; Energy Independence, Storage and Security; Energy Independence and Security Act... and Resiliency; Integra, TheCapitol.Net Inc., 2009

3. D. Bohn, "Micro Gas Turbine and Fuel Cell-A Hybrid Energy Conversion System with High Potential." NATO Research and Technology Organisation, 2005

4. I.A. Popov, Y.F. Gortyshov, and V.V. Olimpiev, Industrial Applications of Heat Transfer Enhancement: The Modern State of the Problem (A Review), Therm. Eng., 2012, 59(1), p 1-12

5. M. Iyengar and A. Bar-Cohen, Design for Manufacturability of SISE Parallel Plate Forced Convection Heat Sinks, IEEE Trans. Compon. Packag. Technol., 2001, 24(2), p 150-158

6. M. Geiger, M. Kleiner, R. Eckstein, N. Tiesler, and U. Engel, Microforming, CIRP Ann. Manuf. Technol., 2001, 50(2), p 445462

7. Y. Jeon and F.E. Pfefferkorn, Effect of Laser Preheating Workpiece on Micro end Milling of Metals, J. Manuf. Sci. Eng., 2008, 130(1), p 1-9

8. K.A. Moores and Y. Joshi, Effect of Tip Clearance on the Thermal and Hydrodynamic Performance of a Shrouded Pin Fin Array, J. Heat Transfer, 2003, 125, p 999-1006

9. K. Thulukkanam, Heat Exchanger Design Handbook, 2nd ed., CRC Press, Boca Raton, 2013

10. W.M. Kays and A.L. London, Compact Heat Exchangers, 3rd ed., McGraw-Hill, New York, 1984

11. F.P. Incropera, D.P. DeWitt, T.L. Bergman, and A.S. Lavine, Fundamentals of Heat and Mass Transfer, 6th ed., Wiley, New York, 2006
12. Y. Cormier, P. Dupuis, B. Jodoin, and A. Corbeil, Net Shape Fins for Compact Heat Exchanger Produced by Cold Spray, J. Therm. Spray Technol., 2013, 22(7), p 1210-1221

13. P. Dupuis, Y. Cormier, A. Farjam, B. Jodoin, and A. Corbeil, Performance Evaluation of Near-Net Pyramidal Shaped Fin Arrays Manufactured by Cold Spray, Int. J. Heat Mass Transf., 2014, 69, p 34-43

14. H. Assadi, F. Gärtner, T. Stoltenhoff, and H. Kreye, Bonding Mechanism in Cold Gas Spraying, Acta Mater., 2003, 51, p 43794394

15. M. Grujicic, C.L. Zhao, W.S. DeRosset, and D. Helfritch, Adiabatic Shear Instability Based Mechanism for Particles/Substrate Bonding in the Cold-Gas Dynamic-Spray Process, Mater. Des., 2004, 25, p 681-688

16. Y. Cormier, P. Dupuis, A. Farjam, A. Corbeil, and B. Jodoin, Additive Manufacturing of Pyramidal Pin Fins: Height and Fin Density Effects under Forced Convection, Int. J. Heat Mass Transf., 2014, 75, p 235-244

17. Y. Cormier, P. Dupuis, B. Jodoin, and A. Corbeil, Mechanical Properties of Cold Gas Dynamic-Sprayed Near-Net-Shaped Fin Arrays, J. Therm. Spray Technol., 2015, 24(3), p 476-488

18. S. Naik, S.D. Probert, and M.J. Shilston, Forced Convective Steady-state Heat Transfers from Shrouded Vertical Fin Arrays Aligned Parallel to an Undisturbed Air-stream, Appl. Energy, 1987, 26, p 137-158

19. J.J. Hwang and T.M. Liou, Heat Transfer and Friction in a Lowaspect-ratio Rectangular Channel with Staggered Perforated Ribs on Two Opposite Walls, ASME J. Heat Transfer, 1995, 117(11), p 843-850

20. N. Sahiti, F. Durst, and A. Dewan, Heat Transfer Enhancement by Pin Elements, Int. J. Heat Mass Transf., 2005, 48, p 4738-4747

21. N. Sahiti, F. Durst, and A. Dewan, Strategy for Selection of Elements for Heat Transfer Enhancement, Int. J. Heat Mass Transf., 2006, 49, p 3392-3400

22. V.K. Champagne, The Cold Spray Materials Deposition Process: Fundamentals and Application, 1st ed., CRC Press, Boca Raton, 2007

23. D. Seo, K. Ogawa, K. Sakaguchi, N. Miyamoto, and Y. Tsuzuki, Parameter Study Influencing Thermal Conductivity of Annealed Pure Copper Coatings Deposited by Selective Cold Spray, Surf. Coat. Technol., 2012, 206, p 2316-2324

24. S. Kikuchi, S. Yoshino, M. Yamada, M. Fukumoto, and K. Okamoto, Microstructures and Thermal Properties Cold-Sprayed Cu-Cr Composite Coatings, J. Therm. Spray Technol., 2013, 22(6), p 926-931

25. E. Litovsky, J.I. Kleiman, M. Shagalov, and R.B. Heimann, Measurement of the Thermal Conductivity of Cold Gas Dynamically Sprayed Alumina-reinforced Aluminum Coatings between $-150^{\circ} \mathrm{C}$ and $+200^{\circ} \mathrm{C}$. New Test Method and Experimental Results, Surf. Coat. Technol., 2014, 242, p 141-145

26. L. Xiao-wei, M. Ji-an, and L. Zhi-xin, Roughness Enhanced Mechanism for Turbulent Convective Heat Transfer, Int. J. Heat Mass Transf., 2011, 54, p 1775-1781

27. G. Croce, P. D'agaro, and C. Nonino, Three-dimensional Roughness Effect on Microchannel Heat Transfer and Pressure Drop, Int. J. Heat Mass Transf., 2007, 50, p 5249-5259

28. L. Ventola, F. Robotti, M. Dialameh, F. Calignano, D. Manfredi, E. Chiavazzo, and P. Asinari, Rough Surfaces with Enhanced Heat Transfer for Electronics Cooling by Direct Metal Laser Sintering, Int. J. Heat Mass Transf., 2014, 75, p 58-74

29. S. Kandlikar, S. Joshi, and S. Tian, Effect of Surface Roughness on Heat Transfer and Fluid Flow Characteristics at Low Reynolds Numbers in Small Diameter Tubes, Heat Transfer Eng., 2010, 24(3), p 4-16 